\title{
Concurrent chemoradiotherapy degrades the quality of life of patients with stage II nasopharyngeal carcinoma as compared to radiotherapy
}

\author{
Xin-Bin Pan ${ }^{1}$, Shi-Ting Huang ${ }^{1}$, Kai-Hua Chen ${ }^{1}$, Yan-Ming Jiang ${ }^{1}$, Jia-Lin Ma ${ }^{1}$, Song \\ Qu ${ }^{1}$, Ling $\mathrm{Li}^{1}$, Long Chen ${ }^{1}$, Xiao-Dong Zhu ${ }^{1}$ \\ ${ }^{1}$ Department of Radiation Oncology, Cancer Hospital of Guangxi Medical University, Nanning, Guangxi 530021, P.R. China \\ Correspondence to: Xiao-Dong Zhu, email: zhuxiaodonggx@163.com \\ Keywords: nasopharyngeal carcinoma, quality of life, radiotherapy, concurrent chemoradiotherapy \\ Received: September 20,2016 Accepted: December 28, $2016 \quad$ Published: February 01, 2017
}

\section{ABSTRACT}

The purpose of this study was to compare the quality of life (QoL) of stage II nasopharyngeal carcinoma (NPC) patients treated with radiotherapy (RT) versus concurrent chemoradiotherapy (CCRT). In a cross-sectional study, these patients were treated with RT $(n=55)$ or CCRT $(n=51)$ between June 2008 and June 2013. For all subjects, disease-free survival was more than 3 years. QoL was assessed using the European Organization for Research and Treatment of Cancer Quality of Life Questionnaire-Core 30 (EORTC QLQ-C30) questions and the Head and Neck 35 (EORTC QLQ-H\&N35) questions. RT had better outcomes than CCRT for global QoL, functional scales, symptom scales of fatigue and insomnia, financial problems, and weight gain. Survivors receiving 1 cycle of concurrent chemotherapy had worse QoL outcomes than survivors receiving 2 cycles of concurrent chemotherapy. Patients receiving 3 cycles of concurrent chemotherapy had the best QoL outcomes. Thus, CCRT adversely affects the QoL of patients with stage II NPC as compared to radiotherapy.

\section{INTRODUCTION}

Nasopharyngeal carcinoma (NPC) is an endemic disease in southern China. The incidence of stage II NPC has greatly increased with improvements in diagnosis. Radiotherapy (RT) or concurrent chemoradiotherapy (CCRT) are the primary treatment modalities for stage II NPC. CCRT is recommended by the National Comprehensive Cancer Network, but the evidence is weak [1-4]. However, RT is recommended by the Chinese Anti-Cancer Association because CCRT does not improve survival, but increases toxic reactions [5-9]. The best treatment modality is still controversial.

After treatment, the 5-year disease-specific survival rate is as high as $97.3 \%$ for stage II NPC [7]. The high survival rate makes QoL increasingly important. Clinicians should pay more attention to QoL because long-term survivors may have problems with swallowing, hearing, and speech, as well as psychological and functional problems. However, previous studies mainly focused on endpoints of overall survival, disease-free survival, or local control rate [1-9]. These endpoints lack information on patients' experience with treatment-related toxicities or QoL.

We conducted a cross-sectional study to compare the QoL of patients with stage II NPC treated with RT versus CCRT. The result of this study might help clinicians make treatment decisions and provide information to health workers on which health services are most beneficial.

\section{RESULTS}

Patients

From June 2008 to June 2013, 235 patients with stage II NPC received radical treatment in the Cancer Hospital of Guangxi Medical University. This study excluded 129 patients. Among the excluded patients, 8 were lost to follow-up, 4 received induced chemotherapy, 40 received adjuvant chemotherapy, 5 died, 9 were locoregional failures, 7 were distant failures, 51 were noncompliant, and 5 did not complete the questionnaire. We included 106 patients treated with RT $(\mathrm{n}=55)$ or CCRT (n $=51$ ). Disease-free survival of all subjects was more than 3 years. Table 1 summarizes patient characteristics. 
Table 1: Patient characteristics

\begin{tabular}{|c|c|c|c|}
\hline & RT $(n=55)$ & $\operatorname{CCRT}(n=51)$ & $\boldsymbol{P}$ \\
\hline \multicolumn{4}{|l|}{ Gender } \\
\hline Male & $38(69.10 \%)$ & $32(62.75 \%)$ & 0.473 \\
\hline Female & $17(30.90 \%)$ & $19(37.25 \%)$ & 0.739 \\
\hline \multicolumn{4}{|l|}{ Age (years) } \\
\hline Median & 43 & 42 & 0.915 \\
\hline Range & $27-68$ & $22-64$ & \\
\hline \multicolumn{4}{|c|}{ Follow-up (months) } \\
\hline Median & 62 & 48 & 0.000 \\
\hline Range & $42-89$ & $38-62$ & \\
\hline \multicolumn{4}{|l|}{ AJCC stage } \\
\hline T1N1M0 & $10(18.18 \%)$ & $11(21.57 \%)$ & 0.827 \\
\hline T2N0M0 & $19(34.55 \%)$ & $5(9.80 \%)$ & 0.004 \\
\hline T2N1M0 & $26(47.27 \%)$ & $35(68.63)$ & 0.249 \\
\hline \multicolumn{4}{|c|}{ Chemotherapy } \\
\hline 1 cycle & I & $6(11.76 \%)$ & \\
\hline 2 cycles & / & $18(35.29 \%)$ & \\
\hline 3 cycles & / & $27(52.95 \%)$ & \\
\hline \multicolumn{4}{|c|}{ Radiotherapy } \\
\hline 2D-CRT & $33(60.00 \%)$ & $14(27.45 \%)$ & 0.006 \\
\hline IMRT & $22(40.00 \%)$ & $37(72.55 \%)$ & 0.051 \\
\hline
\end{tabular}

RT: radiotherapy.

CCRT: concurrent chemoradiotherapy.

2D-CRT: two-dimensional conventional radiotherapy.

IMRT: intensity-modulated radiotherapy.

\section{QoL of RT versus CCRT for the whole group}

RT had higher mean scores in global QoL, physical functioning, role functioning, and emotional functioning but lower mean scores in fatigue, insomnia, financial problems and weight gain compared with CCRT (Table 2). Clinically relevant QoL was significant on the scales of role functioning, emotional functioning, fatigue, insomnia, financial problems, and weight gain based on clinical interpretation (difference in mean scores $\geq 10$ points). The result indicates that CCRT adversely affects the QoL of patients with stage II NPC versus RT.

\section{QoL of RT versus CCRT by different radiotherapy techniques}

In the two-dimensional conventional radiotherapy (2D-CRT) subgroup, RT $(\mathrm{n}=33)$ had better QoL than CCRT $(\mathrm{n}=14)$. Differences between the two groups were clinically relevant (Table 3 ). Moreover, the intensity modulated radiotherapy (IMRT) subgroup had similar results between RT $(\mathrm{n}=22)$ and CCRT $(\mathrm{n}=37)($ Table 4$)$. Despite the radiation technique used (2D-CRT or IMRT), RT resulted in better QoL versus CCRT.

\section{Comparisons of QoL scales by different chemotherapy cycles}

In the CCRT subgroup, 6 patients received 1 cycle of concurrent chemotherapy, 18 patients received 2 cycles of concurrent chemotherapy, and 27 patients received 3 cycles of concurrent chemotherapy. Survivors who received 1 cycle of concurrent chemotherapy had worse QoL outcomes than survivors who received 2 cycles of concurrent chemotherapy. Patients who received 3 cycles of concurrent chemotherapy had the best QoL outcomes (Table 5). Differences among most scales were clinically relevant. The unexpected results may indicate that survivors who are not tolerant of concurrent chemotherapy will have a worse QoL. 
Table 2: Mean quality of life scores of RT versus CCRT for the whole group

\begin{tabular}{|c|c|c|c|c|c|c|}
\hline \multirow{2}{*}{ Scales } & \multicolumn{2}{|c|}{ RT $(n=55)$} & \multicolumn{2}{|c|}{$\operatorname{CCRT}(n=51)$} & \multirow{2}{*}{ T-test } & \multirow{2}{*}{$P$} \\
\hline & Mean & SD & Mean & SD & & \\
\hline \multicolumn{7}{|l|}{ EORTC QLQ-C30 } \\
\hline Global quality of life & 76.67 & 16.15 & 67.81 & 16.92 & 9.082 & 0.000 \\
\hline Physical functioning & 87.39 & 17.67 & 80.26 & 17.23 & 2.102 & 0.038 \\
\hline Role functioning & 87.88 & 18.27 & 76.80 & 19.46 & 3.024 & 0.003 \\
\hline Emotional functioning & 82.73 & 22.79 & 71.90 & 24.55 & 2.356 & 0.020 \\
\hline Cognitive functioning & 77.88 & 27.79 & 69.28 & 22.20 & 1.751 & 0.083 \\
\hline Social functioning & 78.79 & 24.52 & 73.20 & 22.63 & 1.216 & 0.227 \\
\hline Fatigue & 18.59 & 19.13 & 28.76 & 23.85 & -2.431 & 0.017 \\
\hline Nausea/emesis & 3.03 & 7.92 & 2.29 & 6.68 & 0.520 & 0.604 \\
\hline Pain & 10.30 & 15.21 & 15.36 & 14.85 & -1.730 & 0.087 \\
\hline Dyspnea & 6.06 & 12.97 & 9.15 & 18.95 & -0.986 & 0.327 \\
\hline Insomnia & 21.82 & 22.42 & 34.64 & 28.25 & -2.597 & 0.011 \\
\hline Appetite loss & 8.48 & 16.00 & 7.19 & 15.37 & 0.424 & 0.672 \\
\hline Constipation & 4.85 & 16.25 & 4.58 & 17.66 & 0.083 & 0.934 \\
\hline Diarrhea & 4.85 & 14.93 & 5.88 & 12.83 & -0.381 & 0.704 \\
\hline Financial problems & 27.27 & 28.03 & 41.18 & 27.15 & -2.590 & 0.011 \\
\hline \multicolumn{7}{|l|}{ EORTC QLQ-H\&N35 } \\
\hline Pain & 7.12 & 12.05 & 8.17 & 7.54 & -0.532 & 0.596 \\
\hline Swallowing & 14.09 & 17.41 & 17.48 & 15.21 & -1.065 & 0.289 \\
\hline Senses & 16.67 & 16.97 & 17.32 & 17.31 & -0.196 & 0.845 \\
\hline Speech & 6.26 & 10.20 & 5.88 & 9.78 & 0.196 & 0.845 \\
\hline Social contact & 14.70 & 21.03 & 19.61 & 19.42 & -1.246 & 0.216 \\
\hline Social eating & 7.39 & 10.79 & 6.67 & 10.41 & 0.353 & 0.725 \\
\hline Sexuality & 33.03 & 31.99 & 43.46 & 29.83 & -1.733 & 0.086 \\
\hline Teeth & 27.88 & 31.27 & 32.03 & 25.79 & -0.747 & 0.457 \\
\hline Opening mouth & 16.97 & 23.89 & 20.26 & 22.19 & -0.733 & 0.465 \\
\hline Dry mouth & 39.39 & 28.75 & 39.22 & 28.83 & 0.032 & 0.975 \\
\hline Sticky saliva & 4.85 & 13.48 & 7.84 & 19.54 & -0.924 & 0.358 \\
\hline Coughing & 10.30 & 18.00 & 13.07 & 16.44 & -0.825 & 0.411 \\
\hline Feeling ill & 13.33 & 19.88 & 15.69 & 20.39 & -0.601 & 0.549 \\
\hline Pain killers & 5.45 & 22.92 & 9.80 & 30.03 & -0.842 & 0.402 \\
\hline Nutritional supplements & 45.45 & 57.15 & 58.82 & 49.71 & -1.281 & 0.203 \\
\hline Feeding tube & 0.00 & 0.00 & 0.00 & 0.00 & 0.000 & 1.000 \\
\hline Weight loss & 5.45 & 22.92 & 13.73 & 34.75 & -1.435 & 0.155 \\
\hline Weight gain & 1.82 & 13.48 & 35.29 & 48.26 & -4.783 & 0.000 \\
\hline
\end{tabular}

RT: radiotherapy.

CCRT: concurrent chemoradiotherapy.

SD: standard deviation.

EORTC QOL-C30: European Organization for Research and Treatment of Cancer

Quality of Life Questionnaire-Core 30.

EORTC QOL-H\&N35: The EOTRC Quality of Life Questionnaire-Head and Neck 35. 
Table 3: Mean values for all scales of RT versus CCRT with 2D-CRT technique

\begin{tabular}{|c|c|c|c|c|c|c|}
\hline \multirow{2}{*}{ Scales } & \multicolumn{2}{|c|}{ RT $(n=33)$} & \multicolumn{2}{|c|}{$\operatorname{CCRT}(n=14)$} & \multirow{2}{*}{ T-test } & \multirow{2}{*}{$\boldsymbol{P}$} \\
\hline & Mean & SD & Mean & SD & & \\
\hline \multicolumn{7}{|l|}{ EORTC QLQ-C30 } \\
\hline Global quality of life & 69.95 & 15.30 & 53.57 & 11.65 & -3.580 & 0.001 \\
\hline Physical functioning & 80.61 & 19.10 & 64.29 & 14.93 & -2.843 & 0.007 \\
\hline Role functioning & 80.81 & 20.46 & 59.52 & 19.30 & -3.314 & 0.002 \\
\hline Emotional functioning & 74.49 & 23.75 & 50.60 & 26.65 & -3.043 & 0.004 \\
\hline Cognitive functioning & 66.67 & 30.33 & 47.62 & 22.51 & -2.110 & 0.040 \\
\hline Social functioning & 66.67 & 24.65 & 48.81 & 19.02 & -2.417 & 0.020 \\
\hline Fatigue & 26.94 & 19.84 & 51.59 & 17.76 & 4.012 & 0.000 \\
\hline Nausea/emesis & 4.04 & 9.35 & 4.76 & 7.81 & 0.253 & 0.801 \\
\hline Pain & 13.64 & 17.90 & 28.57 & 10.19 & 2.916 & 0.006 \\
\hline Dyspnea & 9.09 & 15.08 & 16.67 & 17.30 & 1.508 & 0.139 \\
\hline Insomnia & 28.28 & 20.62 & 61.90 & 22.10 & 5.006 & 0.000 \\
\hline Appetite loss & 14.14 & 18.69 & 19.05 & 17.12 & 0.843 & 0.404 \\
\hline Constipation & 8.08 & 20.46 & 4.76 & 12.10 & -0.564 & 0.575 \\
\hline Diarrhea & 7.07 & 18.18 & 14.29 & 17.12 & 1.265 & 0.212 \\
\hline Financial problems & 39.39 & 28.20 & 57.14 & 20.37 & 2.125 & 0.039 \\
\hline \multicolumn{7}{|l|}{ EORTC QLQ-H\&N35 } \\
\hline Pain & 10.86 & 14.05 & 13.10 & 7.10 & 0.563 & 0.576 \\
\hline Swallowing & 22.22 & 18.00 & 33.93 & 14.05 & 2.165 & 0.036 \\
\hline Senses & 23.74 & 17.69 & 28.57 & 17.82 & 0.855 & 0.397 \\
\hline Speech & 9.43 & 11.82 & 13.49 & 10.83 & 1.104 & 0.276 \\
\hline Social contact & 24.24 & 22.57 & 39.88 & 18.83 & 2.275 & 0.028 \\
\hline Social eating & 12.12 & 11.72 & 14.29 & 13.30 & 0.556 & 0.581 \\
\hline Sexuality & 47.47 & 30.08 & 72.62 & 30.39 & 2.613 & 0.012 \\
\hline Teeth & 40.40 & 32.01 & 54.76 & 21.11 & 1.537 & 0.131 \\
\hline Opening mouth & 27.27 & 25.62 & 33.33 & 18.49 & 0.799 & 0.429 \\
\hline Dry mouth & 54.55 & 23.30 & 66.67 & 18.49 & 1.896 & 0.067 \\
\hline Sticky saliva & 7.07 & 16.15 & 16.67 & 21.68 & 1.490 & 0.152 \\
\hline Coughing & 10.10 & 17.65 & 21.43 & 16.57 & 2.048 & 0.046 \\
\hline Feeling ill & 18.18 & 20.57 & 33.33 & 18.49 & 2.483 & 0.019 \\
\hline Pain killers & 3.03 & 9.73 & 2.38 & 8.91 & -0.214 & 0.831 \\
\hline Nutritional supplements & 21.21 & 20.10 & 28.57 & 12.10 & 1.544 & 0.131 \\
\hline Feeding tube & 0.00 & 0.00 & 0.00 & 0.00 & 0.000 & 1.000 \\
\hline Weight loss & 2.02 & 8.08 & 14.29 & 17.12 & 3.359 & 0.002 \\
\hline Weight gain & 1.01 & 5.80 & 4.76 & 12.10 & 1.107 & 0.285 \\
\hline
\end{tabular}

2D-CRT: two-dimensional conventional radiotherapy.

RT: radiotherapy.

CCRT: concurrent chemoradiotherapy.

SD: standard deviation.

EORTC QOL-C30: European Organization for Research and Treatment of Cancer

Quality of Life Questionnaire-Core 30.

EORTC QOL-H\&N35: The EOTRC Quality of Life Questionnaire-Head and Neck 35. 
Table 4: Mean values for all scales of RT versus CCRT with IMRT technique

\begin{tabular}{|c|c|c|c|c|c|c|}
\hline \multirow{2}{*}{ Scales } & \multicolumn{2}{|c|}{ RT $(n=22)$} & \multicolumn{2}{|c|}{$\operatorname{CCRT}(n=37)$} & \multirow{2}{*}{ T-test } & \multirow{2}{*}{$\boldsymbol{P}$} \\
\hline & Mean & SD & Mean & SD & & \\
\hline \multicolumn{7}{|l|}{ EORTC QLQ-C30 } \\
\hline Global quality of life & 86.31 & 12.49 & 79.04 & 16.42 & 1.481 & 0.146 \\
\hline Physical functioning & 97.62 & 8.91 & 89.90 & 14.45 & 2.229 & 0.032 \\
\hline Role functioning & 98.81 & 4.45 & 86.87 & 16.01 & 3.941 & 0.000 \\
\hline Emotional functioning & 92.26 & 17.74 & 87.63 & 14.75 & 0.927 & 0.359 \\
\hline Cognitive functioning & 95.24 & 10.19 & 84.34 & 13.14 & 2.764 & 0.008 \\
\hline Social functioning & 98.81 & 4.45 & 87.88 & 14.60 & 3.895 & 0.000 \\
\hline Fatigue & 4.76 & 7.18 & 15.82 & 20.04 & -2.779 & 0.008 \\
\hline Nausea/emesis & 2.38 & 6.05 & 0.51 & 2.90 & 1.107 & 0.285 \\
\hline Pain & 5.95 & 8.29 & 9.09 & 13.24 & -0.982 & 0.332 \\
\hline Dyspnea & 2.38 & 8.91 & 6.06 & 19.46 & -0.675 & 0.503 \\
\hline Insomnia & 11.90 & 24.83 & 22.22 & 24.53 & -1.314 & 0.196 \\
\hline Appetite loss & 0.00 & 0.00 & 2.02 & 11.61 & -0.647 & 0.521 \\
\hline Constipation & 0.00 & 0.00 & 5.05 & 20.62 & -0.911 & 0.367 \\
\hline Diarrhea & 2.38 & 8.91 & 3.03 & 9.73 & -0.214 & 0.831 \\
\hline Financial problems & 7.14 & 14.19 & 27.27 & 25.62 & -3.438 & 0.001 \\
\hline \multicolumn{7}{|l|}{ EORTC QLQ-H\&N35 } \\
\hline Pain & 2.38 & 5.09 & 3.79 & 5.55 & -0.814 & 0.420 \\
\hline Swallowing & 2.98 & 6.21 & 6.31 & 9.78 & -1.404 & 0.169 \\
\hline Senses & 8.33 & 8.65 & 13.13 & 16.01 & -1.054 & 0.298 \\
\hline Speech & 1.59 & 4.03 & 3.37 & 8.09 & -0.779 & 0.440 \\
\hline Social contact & 0.00 & 0.00 & 6.82 & 12.58 & -3.114 & 0.004 \\
\hline Social eating & 0.48 & 1.78 & 3.43 & 7.66 & -2.089 & 0.043 \\
\hline Sexuality & 4.76 & 10.19 & 27.78 & 20.27 & -5.164 & 0.000 \\
\hline Teeth & 7.14 & 14.19 & 16.16 & 20.62 & -1.727 & 0.093 \\
\hline Opening mouth & 2.38 & 8.91 & 9.09 & 15.08 & -1.894 & 0.066 \\
\hline Dry mouth & 19.05 & 21.54 & 24.24 & 26.71 & -0.643 & 0.523 \\
\hline Sticky saliva & 2.38 & 8.91 & 5.05 & 18.86 & -0.504 & 0.617 \\
\hline Coughing & 14.29 & 21.54 & 11.11 & 15.96 & 0.561 & 0.578 \\
\hline Feeling ill & 2.38 & 8.91 & 11.11 & 19.84 & -2.081 & 0.043 \\
\hline Pain killers & 0.00 & 0.00 & 4.04 & 11.05 & -2.101 & 0.044 \\
\hline Nutritional supplements & 0.00 & 0.00 & 17.17 & 16.92 & -5.831 & 0.000 \\
\hline Feeding tube & 0.00 & 0.00 & 0.00 & 0.00 & 0.000 & 1.000 \\
\hline Weight loss & 2.38 & 8.91 & 1.01 & 5.80 & 0.628 & 0.533 \\
\hline Weight gain & 0.00 & 0.00 & 11.11 & 15.96 & -4.000 & 0.000 \\
\hline
\end{tabular}

IMRT: intensity-modulated radiotherapy.

RT: radiotherapy.

CCRT: concurrent chemoradiotherapy.

SD: standard deviation.

EORTC QOL-C30: European Organization for Research and Treatment of Cancer

Quality of Life Questionnaire-Core 30.

EORTC QOL-H\&N35: The EOTRC Quality of Life Questionnaire-Head and Neck 35. 
Table 5: Comparisons of mean values for all scales by different chemotherapy cycles

\begin{tabular}{|c|c|c|c|c|c|c|c|c|}
\hline \multirow{2}{*}{ Scales } & \multicolumn{2}{|c|}{1 cycle $C T(n=6)$} & \multicolumn{2}{|c|}{2 cycles $C T(n=18)$} & \multicolumn{2}{|c|}{3 cycles $C T(n=27)$} & \multirow{2}{*}{ F-test } & \multirow{2}{*}{$P$} \\
\hline & Mean & SD & Mean & SD & Mean & SD & & \\
\hline \multicolumn{9}{|l|}{ EORTC QLQ-C30 } \\
\hline Global quality of life & 54.17 & 10.21 & 66.67 & 13.71 & 72.12 & 18.85 & 3.023 & 0.058 \\
\hline Physical functioning & 57.78 & 15.01 & 80.00 & 14.99 & 86.41 & 14.79 & 9.048 & 0.000 \\
\hline Role functioning & 58.33 & 20.41 & 75.00 & 17.39 & 83.97 & 15.97 & 5.884 & 0.005 \\
\hline Emotional functioning & 47.22 & 22.77 & 67.13 & 27.19 & 81.73 & 17.80 & 6.687 & 0.003 \\
\hline Cognitive functioning & 36.11 & 16.39 & 69.44 & 22.32 & 78.21 & 13.96 & 13.836 & 0.000 \\
\hline Social functioning & 47.22 & 16.39 & 65.74 & 23.20 & 85.26 & 15.15 & 12.769 & 0.000 \\
\hline Fatigue & 50.00 & 15.32 & 33.95 & 24.84 & 19.66 & 21.15 & 5.493 & 0.007 \\
\hline Nausea/emesis & 2.78 & 6.80 & 4.63 & 9.58 & 0.00 & 0.00 & 3.047 & 0.057 \\
\hline Pain & 27.78 & 13.61 & 16.67 & 15.12 & 10.90 & 13.29 & 3.737 & 0.031 \\
\hline Dyspnea & 16.67 & 18.26 & 5.56 & 12.78 & 8.97 & 22.23 & 0.785 & 0.462 \\
\hline Insomnia & 55.56 & 17.21 & 40.74 & 24.40 & 24.36 & 29.15 & 4.309 & 0.019 \\
\hline Appetite loss & 16.67 & 18.26 & 7.41 & 14.26 & 3.85 & 14.38 & 1.864 & 0.166 \\
\hline Constipation & 0.00 & 0.00 & 1.85 & 7.86 & 7.69 & 23.68 & 0.798 & 0.456 \\
\hline Diarrhea & 11.11 & 17.21 & 5.56 & 12.78 & 5.13 & 12.26 & 0.528 & 0.593 \\
\hline Financial problems & 55.56 & 17.21 & 37.04 & 25.28 & 39.74 & 29.84 & 1.079 & 0.348 \\
\hline \multicolumn{9}{|l|}{ EORTC QLQ-H\&N35 } \\
\hline Pain & 13.89 & 6.80 & 7.87 & 6.69 & 7.05 & 8.06 & 2.070 & 0.138 \\
\hline Swallowing & 36.11 & 13.61 & 20.37 & 14.64 & 10.26 & 10.62 & 11.381 & 0.000 \\
\hline Senses & 30.56 & 19.48 & 19.44 & 16.42 & 12.82 & 16.54 & 2.927 & 0.063 \\
\hline Speech & 14.81 & 9.07 & 4.32 & 9.44 & 5.13 & 9.55 & 2.998 & 0.059 \\
\hline Social contact & 47.22 & 17.21 & 21.30 & 17.44 & 11.22 & 14.52 & 12.709 & 0.000 \\
\hline Social eating & 21.11 & 14.25 & 4.07 & 7.97 & 4.87 & 8.55 & 8.724 & 0.001 \\
\hline Sexuality & 91.67 & 20.41 & 48.15 & 28.52 & 28.21 & 17.49 & 20.327 & 0.000 \\
\hline Teeth & 55.56 & 17.21 & 37.04 & 22.55 & 21.79 & 24.84 & 5.952 & 0.005 \\
\hline Opening mouth & 44.44 & 17.21 & 20.37 & 16.72 & 14.10 & 23.42 & 5.291 & 0.008 \\
\hline Dry mouth & 61.11 & 25.09 & 38.89 & 23.57 & 33.33 & 31.27 & 2.388 & 0.103 \\
\hline Sticky saliva & 11.11 & 17.21 & 9.26 & 19.15 & 6.41 & 21.12 & 0.190 & 0.828 \\
\hline Coughing & 27.78 & 13.61 & 11.11 & 16.17 & 11.54 & 16.17 & 2.811 & 0.070 \\
\hline Feeling ill & 27.78 & 13.61 & 20.37 & 23.26 & 8.97 & 17.78 & 3.177 & 0.051 \\
\hline Pain killers & 0.00 & 0.00 & 3.70 & 10.78 & 3.85 & 10.86 & 0.363 & 0.698 \\
\hline Nutritional supplements & 22.22 & 17.21 & 18.52 & 17.04 & 19.23 & 16.79 & 0.109 & 0.897 \\
\hline Feeding tube & 0.00 & 0.00 & 0.00 & 0.00 & 0.00 & 0.00 & 0.000 & 1.000 \\
\hline Weight loss & 16.67 & 18.26 & 5.56 & 12.78 & 1.28 & 6.54 & 5.013 & 0.011 \\
\hline Weight gain & 0.00 & 0.00 & 11.11 & 16.17 & 15.38 & 16.95 & 2.378 & 0.104 \\
\hline
\end{tabular}

CT: chemotherapy.

SD: standard deviation.

EORTC QOL-C30: European Organization for Research and Treatment of Cancer Quality of Life Questionnaire-Core 30.

EORTC QOL-H\&N35: The EOTRC Quality of Life Questionnaire-Head and Neck 35. 


\section{DISCUSSION}

The study suggests that RT has better outcomes in global QoL and functional scales of EORTC QLQ-C30 compared with CCRT. The result might help clinicians make better treatment decisions and provide information to health workers on which health services are most beneficial.

Different questionnaires were used for QoL assessment in NPC patients. A few studies used the EORTC QLQ-C30 questionnaire and the EORTC QLQH\&N35 questionnaire [10-13]. Some studies used the Functional Assessment of Cancer Therapy-General (FACT-G) scale, the Functional Assessment of Cancer Therapy-Head and Neck (FACT-H\&N) module [14, 15], and the Functional Assessment of Cancer TherapyNasopharyngeal (FACT-NP) subscale [16]. Other studies used the MOS 36-item short-form health survey (SF-36) $[17,18]$ and the University of Washington Quality of Life Questionnaire [19]. Recently, an NPC-specific scale (QoLNPC) was developed to assess the physical functioning and health status of Chinese NPC patients [20]. However, FACT-NP has not been updated. SF-36 and the University of Washington Quality of Life Questionnaire are not specific questionnaires for QoL assessment in head-andneck cancer patients, and QoL-NPC should be further evaluated by a large sample from different centers.

In this study, we used EORTC QLQ-C30 and the EORTC QLQ-H\&N35 for QoL assessment because the two questionnaires are comprehensive. The EORTC QLQ-C30 contains a range of QoL issues related to different cancer patients, including head-and-neck cancer. The EORTC QLQ-C30 has been translated into many languages and is a widely used questionnaire. The QLQH\&N35 is used to assess the QoL of patients with headand-neck cancer specifically. The EORTC QLQ-C30 and the EORTC QLQ-H\&N35 questionnaires are valid, internally consistency, and reliable in patients from different nations and were tested in large patient groups [21]. The Chinese version of the EORTC QLQ-C30 and the EORTC QLQ-H\&N35 were previously tested, confirmed, and validated by some studies [11-13].

Our study showed no significant difference between RT and CCRT groups, except for weight gain reported in the EORTC QLQ-H\&N35 questionnaire. The potential reasons are the following: (1) The EORTC QLQ-H\&N35 might have some limitations in assessing QoL of NPC patients, although the EORTC QLQ-H\&N35 is a specific questionnaire for assessing the QoL of head-and-neck cancer patients. NPC is different from other head-and-neck cancers because of its location, biological characteristics, and treatment. NPC survivors might experience deafness, otitis media, symptoms from temporal lobe injury, and hypopituitarism after radiotherapy. The EORTC QLQH\&N35 does not deal with these adverse effects well enough. (2) CCRT was suggested to cause statistically significantly more acute toxic effects but similar late toxic effects compared with RT [4]. This outcome might be interpreted as the result of the few differences between RT and CCRT observed in the symptom scales of the EORTC QLQ-H\&N35.

Previous studies mainly analyzed the effect of different radiotherapy techniques (IMRT vs. 2D-CRT) on QoL [11-13]. Only one study mentioned the effect of chemotherapy on QoL [10]. The above study found that concurrent chemotherapy adversely affected five symptom scales, but did not affect global QoL and functional scales. However, our study observed that concurrent chemotherapy adversely affected not only symptom scales but also global QoL and functional scales. Our results showed that CCRT had higher scores for fatigue and insomnia than did RT. Fatigue and insomnia might be caused by chemotherapy and contribute to loss of physical functioning, role functioning, and emotional functioning. The results of 2D-CRT and IMRT subgroup analysis further confirmed the above conclusion.

Some studies discussed the impact of financial problems on QoL [14, 22]. These studies found that financial difficulties adversely affect QoL. CCRT will increase the expenses of NPC treatment and eventually increase the financial difficulties of individuals in developing countries such as China. Consequently, CCRT adversely affects QoL. But, the relation between financial problems and QoL is still unclear. Further controlled studies should be performed to test the impact of financial difficulties on QoL.

Our result shows that CCRT adversely affects QoL. Thus, we hypothesize that patients who receive more cycles of chemotherapy will experience worse QoL. However, subgroup analyses of the effect of different chemotherapy cycles on QoL show an opposite result. Survivors who received 1 cycle of concurrent chemotherapy had worse QoL outcomes than survivors who received 2 cycles of concurrent chemotherapy. Patients who received 3 cycles of concurrent chemotherapy had the best QoL outcomes.

The potential interpretations are the following: (1) The 6 patients who received 1 cycle of concurrent chemotherapy received only 1 cycle because of serious toxicity during treatment. Serious toxicity made the 6 patients' recovery worse. However, survivors who received 2 or 3 cycles of concurrent chemotherapy better tolerated chemotherapy and recovered better. (2) The 6 patients were all irradiated by 2D-CRT, the 18 patients who received 2 cycles of concurrent chemotherapy were treated with 2D-CRT or IMRT, and the 27 patients who received 3 cycles of concurrent chemotherapy were irradiated mostly by IMRT. Use of IMRT is associated with the reduction of physician-assessed late toxicities and improved patient-reported QoL in NPC survivors [11-13]. (3) Only 6 patients received 1 cycle of concurrent chemotherapy; thus the sample size of the CCRT group 
was insufficient. The result should therefore be treated with caution, and a large sample of patients should be investigated to verify the result.

The limitations of our study must be considered: (1) Only 106 patients were enrolled in our study, and the sample size of the CCRT group was insufficient for comparisons of QoL scales by different chemotherapy cycles. (2) The QoL measurement of our study was conducted at only one time point. A more methodologically sound approach is to use a longitudinal design in which the same individuals are assessed repeatedly at various time points.

\section{MATERIALS AND METHODS}

\section{Study population}

This cross-sectional study analyzed QoL data of patients with stage II NPC in the Cancer Hospital of Guangxi Medical University from June 2008 to June 2013. Inclusion criteria were (1) pathologically proved NPC, (2) stage II NPC per the 7th Edition of the UICC/ AJCC staging system, (3) Karnofsky performance status $>70$, (4) receiving radical RT or CCRT, and (5) diseasefree survival $>3$ years. Exclusion criteria were (1) age $>70$ or $<18$ years, (2) recurrent or metastatic NPC, (3) receiving induced or adjuvant chemotherapy, (4) a second malignancy, except for cured skin basal cell carcinoma or early stage cervical cancer, (5) severe cerebral, cardiac, hematologic, renal, hepatic, or mental disease, and (6) incompletion of the self-reporting questionnaire.

\section{Radiotherapy}

Patients received 2D-CRT in two phases. In the first phase, patients were irradiated by 6-megavolt bilateral and opposing photon beams. The dose for faciocervical field and lower anterior cervical field was $36 \mathrm{~Gy}$. In the second phase, the dose for primary tumor was boosted from 66 Gy to 70 Gy. The prescribed irradiation dose was 2 Gy per fraction with 5 daily fractions per week.

Patients received IMRT per the International Commission on Radiation Units and Measurements Report 62 guidelines. Gross tumor volume (GTVnx) and cervical lymph node tumor volume (GTVnd) were defined as gross shown by CT/MRI. Clinical target volume (CTV) included the GTV with a 1-cm to 1.5$\mathrm{cm}$ margin, the entire nasopharyngeal space, and the positive lymph node regions. The prescribed radiation dose was $66 \mathrm{~Gy}$ to $70.06 \mathrm{~Gy}$ in 30 to 31 fractions for GTV, and 54 Gy to 60 Gy in 30 fractions for CTV with 5 daily fractions per week.

\section{Chemotherapy}

Patients received concurrent chemotherapy on days 1,22 , and 43 during radiotherapy. Chemotherapy regimen was cisplatin $100 \mathrm{mg} / \mathrm{m}^{2} / \mathrm{d}$ by intravenous infusion.
Chemotherapy was postponed or discontinued for patients who experienced serious toxicity and could not recover before the next schedule.

\section{QoL measurement}

QoL assessment used the Chinese version of the EORTC QLQ-C30 questions and the EORTC QLQH\&N35 questions [21, 23-25]. The EORTC QLQ-C30 is a cancer-specific questionnaire containing a global QoL score, five functional scales, three symptom scales, and six single items. The QLQ-H\&N35 is a site-specific questionnaire assessing QoL of head-and-neck cancer patients. The QLQ-H\&N35 contains seven multiple-item and six single-item scales. The standard score of all scales ranges from 0 to 100 . A high score for a global QoL or functional scale represents a high/healthy level of global QoL or functioning, whereas a high score for a symptom scale represents a symptom problem. QoL changes of $\geq 10$ points were considered clinically relevant [26, 27].

\section{Statistical analysis}

Statistical analysis was performed using SPSS for Windows version 16.0 (SPSS Inc., Chicago, IL). The $\chi^{2}$ test was used for the comparisons of categorical data. The T-test was used to compare the mean scores of QoL between two groups. The F-test was used for the comparisons among groups. All significant tests were two-sided and $P$ value $<0.05$ was considered statistically significant.

\section{CONCLUSIONS}

This study suggests that CCRT degrades broad aspects of QoL for patients with stage II NPC. RT may be a better treatment choice for stage II NPC compared with CCRT. However, undetected factors still might be related to QoL. The data in this study must be tested, preferably in a prospective, randomized trial.

\section{CONFLICTS OF INTEREST}

The authors declare no conflicts of interest.

\section{ROLE OF THE FUNDING SOURCE}

This study was supported by the Basic Ability Improvement Project for Young and Middle-aged Teachers of Guangxi Zhuang Autonomous Region 2016: KY2016LX029.

\section{REFERENCES}

1. Cheng SH, Tsai SY, Yen KL, Jian JJ, Chu NM, Chan KY, Tan TD, Cheng JC, Hsieh CY, Huang AT. Concomitant 
radiotherapy and chemotherapy for early-stage nasopharyngeal carcinoma. J Clin Oncol. 2000; 18: 2040-5.

2. Cheng SH, Tsai SY, Yen KL, Jian JJ, Feng AC, Chan KY, Hong CF, Chu NM, Lin YC, Lin CY, Tan TD, Hsieh CY, Chong V, et al. Prognostic significance of parapharyngeal space venous plexus and marrow involvement: potential landmarks of dissemination for stage I-III nasopharyngeal carcinoma. Int J Radiat Oncol Biol Phys. 2005; 61: 456-65. doi: 10.1016/j.ijrobp.2004.05.047.

3. Kang MK, Oh D, Cho KH, Moon SH, Wu HG, Heo DS, Ahn YC, Park K, Park HJ, Park JS, Keum KC, Cha J, Kim JW, et al. Role of Chemotherapy in Stage II Nasopharyngeal Carcinoma Treated with Curative Radiotherapy. Cancer Res Treat. 2015; 47: 871-8. doi: 10.4143/crt.2014.141.

4. Chen QY, Wen YF, Guo L, Liu H, Huang PY, Mo HY, Li NW, Xiang YQ, Luo DH, Qiu F, Sun R, Deng MQ, Chen MY, et al. Concurrent chemoradiotherapy vs radiotherapy alone in stage II nasopharyngeal carcinoma: phase III randomized trial. J Natl Cancer Inst. 2011; 103: 1761-70. doi: $10.1093 /$ jnci/djr432.

5. Xu T, Shen C, Zhu G, Hu C. Omission of Chemotherapy in Early Stage Nasopharyngeal Carcinoma Treated with IMRT: A Paired Cohort Study. Medicine (Baltimore). 2015; 94: e1457. doi: 10.1097/MD.0000000000001457.

6. Tham IW, Lin S, Pan J, Han L, Lu JJ, Wee J. Intensitymodulated radiation therapy without concurrent chemotherapy for stage IIb nasopharyngeal cancer. Am J Clin Oncol. 2010; 33: 294-9. doi: 10.1097/ COC.0b013e3181d2edab.

7. Su SF, Han F, Zhao C, Chen CY, Xiao WW, Li JX, Lu TX. Long-term outcomes of early-stage nasopharyngeal carcinoma patients treated with intensity-modulated radiotherapy alone. Int J Radiat Oncol Biol Phys. 2012; 82: 327-33. doi: 10.1016/j.ijrobp.2010.09.011.

8. Guo Q, Lu T, Lin S, Zong J, Chen Z, Cui X, Zhang Y, Pan J. Long-term survival of nasopharyngeal carcinoma patients with Stage II in intensity-modulated radiation therapy era. Jpn J Clin Oncol. 2016; 46: 241-7. doi: 10.1093/jjco/ hyv192.

9. Zhang LN, Gao YH, Lan XW, Tang J, Su Z, Ma J, Deng W, OuYang PY, Xie FY. Propensity score matching analysis of cisplatin-based concurrent chemotherapy in low risk nasopharyngeal carcinoma in the intensity-modulated radiotherapy era. Oncotarget. 2015; 6: 44019-29. doi: 10.18632/oncotarget.5806.

10. Cengiz M, Ozyar E, Esassolak M, Altun M, Akmansu M, Sen M, Uzel O, Yavuz A, Dalmaz G, Uzal C, Hicsonmez A, Sarihan S, Kaplan B, et al. Assessment of quality of life of nasopharyngeal carcinoma patients with EORTC QLQ-C30 and H\&N-35 modules. Int J Radiat Oncol Biol Phys. 2005; 63: 1347-53. doi: 10.1016/j.ijrobp.2005.05.057.

11. Huang TL, Chien CY, Tsai WL, Liao KC, Chou SY, Lin HC, Dean Luo S, Lee TF, Lee CH, Fang FM. Long-term late toxicities and quality of life for survivors of nasopharyngeal carcinoma treated with intensity-modulated radiotherapy versus non-intensity-modulated radiotherapy. Head Neck. 2016; 38 Suppl 1: E1026-32. doi: 10.1002/hed.24150.

12. Song T, Fang M, Zhang XB, Zhang P, Xie RF, Wu SX. Sustained improvement of quality of life for nasopharyngeal carcinoma treated by intensity modulated radiation therapy in long-term survivors. Int J Clin Exp Med. 2015; 8: 5658-66.

13. Fang FM, Tsai WL, Chen HC, Hsu HC, Hsiung CY, Chien CY, Ko SF. Intensity-modulated or conformal radiotherapy improves the quality of life of patients with nasopharyngeal carcinoma: comparisons of four radiotherapy techniques. Cancer. 2007; 109: 313-21. doi: 10.1002/cncr.22396.

14. Yu CL, Fielding R, Chan CL, Sham JS. Chinese nasopharyngeal carcinoma patients treated with radiotherapy: association between satisfaction with information provided and quality of life. Cancer. 2001; 92: 2126-35. doi: 10.1002/cncr.1554.

15. Teckle P, McTaggart-Cowan H, Van der Hoek K, Chia S, Melosky B, Gelmon K, Peacock S. Mapping the FACT-G cancer-specific quality of life instrument to the EQ-5D and SF-6D. Health Qual Life Outcomes. 2013; 11: 203. doi: 10.1186/1477-7525-11-203.

16. Tong MC, Lo PS, Wong KH, Yeung RM, van Hasselt CA, Eremenco S, Cella D. Development and validation of the functional assessment of cancer therapy nasopharyngeal cancer subscale. Head Neck. 2009; 31: 738-47. doi: 10.1002/hed.21023.

17. Gu MF, Su Y, Chen XL, He WL, He ZY, Li JJ, Chen MQ, Mo CW, Xu Q, Diao YM. Quality of life and radiotherapy complications of Chinese nasopharyngeal carcinoma patients at different 3DCRT. Asian Pac J Cancer Prev. 2012; 13: 75-9.

18. Wu Y, Hu WH, Xia YF, Ma J, Liu MZ, Cui NJ. Quality of life of nasopharyngeal carcinoma survivors in Mainland China. Qual Life Res. 2007; 16: 65-74. doi: 10.1007/ s11136-006-9113-0.

19. Chen AM, Farwell DG, Luu Q, Vazquez EG, Lau DH, Purdy JA. Intensity-modulated radiotherapy is associated with improved global quality of life among long-term survivors of head-and-neck cancer. Int J Radiat Oncol Biol Phys. 2012; 84: 170-5. doi: 10.1016/j.ijrobp.2011.11.026.

20. Su Y, Mo CW, Cheng WQ, Wang L, Xu Q, Wu ZC, Wu ZL, Liu LZ, Chen XL. Development and validation of quality of life scale of nasopharyngeal carcinoma patients: the QOLNPC (version 2). Health Qual Life Outcomes. 2016; 14: 76. doi: 10.1186/s12955-016-0480-0.

21. Bjordal K, de Graeff A, Fayers PM, Hammerlid E, van Pottelsberghe C, Curran D, Ahlner-Elmqvist M, Maher EJ, Meyza JW, Bredart A, Soderholm AL, Arraras JJ, Feine JS, et al. A 12 country field study of the EORTC QLQ-C30 (version 3.0) and the head and neck cancer specific module (EORTC QLQ-H\&N35) in head and neck patients. EORTC Quality of Life Group. Eur J Cancer. 2000; 36: 1796-807. 
22. Fang FM, Chiu HC, Kuo WR, Wang CJ, Leung SW, Chen HC, Sun LM, Hsu HC. Health-related quality of life for nasopharyngeal carcinoma patients with cancer-free survival after treatment. Int J Radiat Oncol Biol Phys. 2002; 53: 959-68.

23. Zhao H, Kanda K. Testing psychometric properties of the standard Chinese version of the European Organization for Research and Treatment of Cancer Quality of Life Core Questionnaire 30 (EORTC QLQ-C30). J Epidemiol. 2004; 14: 193-203.

24. Bjordal K, Hammerlid E, Ahlner-Elmqvist M, de Graeff A, Boysen M, Evensen JF, Biorklund A, de Leeuw JR, Fayers PM, Jannert M, Westin T, Kaasa S. Quality of life in head and neck cancer patients: validation of the European Organization for Research and Treatment of Cancer Quality of Life Questionnaire-H\&N35. J Clin Oncol. 1999; 17: 1008-19.

25. Aaronson NK, Ahmedzai S, Bergman B, Bullinger M, Cull A, Duez NJ, Filiberti A, Flechtner H, Fleishman SB, de Haes JC, et al. The European Organization for Research and Treatment of Cancer QLQ-C30: a quality-of-life instrument for use in international clinical trials in oncology. J Natl Cancer Inst. 1993; 85: 365-76.

26. King MT. The interpretation of scores from the EORTC quality of life questionnaire QLQ-C30. Qual Life Res. 1996; 5: 555-67.

27. Osoba D, Rodrigues G, Myles J, Zee B, Pater J. Interpreting the significance of changes in health-related quality-of-life scores. J Clin Oncol. 1998; 16: 139-44. 